\title{
Healthcare-Associated Infections in the Neurocritical Care Unit
}

\author{
Katharina M. Busl ${ }^{1}$ \\ Published online: 27 August 2019 \\ (C) Springer Science+Business Media, LLC, part of Springer Nature 2019
}

\begin{abstract}
Purpose of Review This article summarizes updated data and knowledge on healthcare-associated infections in the neurocritical care unit, with a focus on central nervous system infections and systemic infectious complications in patients with acute brain disease. It also reviews the concept of brain injury-induced immune modulation, an underlying mechanism to explain why the neuro-ICU population is particularly susceptible to infections.

Recent Findings Healthcare-associated infections in the neuro-ICU are common: up to $40 \%$ of meningitides in the developed world are now healthcare-associated. The number of gram-negative infections is rising. New diagnostic approaches attempt to aid in the diagnosis of healthcare-associated meningitis and ventriculitis.

Summary Healthcare-associated infections in the neurocritical care unit remain a challenge for diagnosis, treatment, and prevention. Gaining a better understanding of at-risk patients and development of preventative strategies will be the goal for future investigation.
\end{abstract}

Keywords Healthcare-associated infections $\cdot$ Healthcare-associated meningitis and ventriculitis $\cdot$ Infections in brain injury

\section{Introduction}

Healthcare-associated infections (HAIs) occur in $3.2 \%$ of patients, with pneumonia, Clostridium difficile (C. diff) infections, surgical site infections, and urinary tract infections (UTI) being the most common [1••]. HAIs result in increased morbidity, mortality, and healthcare utilization [3]. General risk factors for HAIs include a longer length of stay (LOS), number of medical comorbidities, presence of invasive devices, and use of antimicrobials [4]. Patients admitted to an ICU are at higher risk for HAI, due to a higher prevalence of immunosuppression, high frequency of indwelling catheters and mechanical ventilation, and presence of multidrugresistant organisms [5]. Among ICU patients, the overall rate of ICU-related infections is estimated to be $15 \%$ [6], and UTI is the most common accounting for as many as $23 \%$ [7]. For patients admitted to the neurointensive care unit (neuro-ICU), the rate of infectious complications reaches up to $36 \%$ when

This article is part of the Topical Collection on Critical Care

Katharina M. Busl

Katharina.bus1@neurology.ufl.edu

1 Departments of Neurology and Neurosurgery, McKnight Brain Institute L3-100, University of Florida College of Medicine, 1149 Newell Drive, Gainesville, FL 32610, USA admitted for more than $48 \mathrm{~h}$ [8]. Among patients undergoing craniotomy, as many as $40 \%$ develop at least one infection, pneumonia being the most common ( $38 \%$ ), followed by UTI $(9 \%)$, and surgical site infection (9\%) [9]. Postoperative meningitis occurs in up to $8.6 \%$ of all patients undergoing cranial neurosurgery, and ventriculostomy-related infection (VRI) occurs in up to $22 \%$ [10॰], although data are heterogeneous due to use of different definitions for infections, and variable exclusion of culture-negative results, making a true estimate of prevalence difficult.

The neuro-ICU population is particularly vulnerable to pneumonias, due to the high rate of dysphagia and risk of aspiration in patients with neurological diseases. Furthermore, the risk of CAUTI is higher in the neuro-ICU population due to the need for catheter placement and maintenance in many brain- or spine-injured patients, and paraplegia and cerebrovascular disease-posing-independent risk factors for CAUTIs [12]. While a population high at risk for HAI, the neuro-ICU population also poses a specific challenge in the diagnosis of infections. Fever is highly prevalent, with an incidence in the first week of hospitalization is as high as $87 \%$ [13], but is oftentimes is a manifestation of the brain injury itself and not infectious in origin. In a prospective study of fever in neuro-ICU patients with an incidence of fever in one of four patients, nearly half were noninfectious in etiology [14]. Lastly, cerebrospinal fluid (CSF) parameters are difficult 
to interpret in the setting of previous antibiotic administration, neurosurgical procedures, or acute brain injury and nervous system disease that alters the profile per se.

\section{Healthcare-associated Meningitis and Ventriculitis (HAMV)}

\section{Infections After Craniotomy}

For the development of post-neurosurgical meningitis, independent risk factors include experience in surgical technique, CSF leaks, concomitant infection at incisional sites, and perioperative steroid use [9]. Tumor surgery, severe head injury, and subarachnoid hemorrhage pose the highest risk for postoperative meningitis [15]. Furthermore, craniotomies with extraventricular drain (EVD) and traumatic brain injury (TBI) requiring craniotomies carry a higher risk for meningitis $[9,16]$. Data on duration and type of surgery are controversial $[9,17]$. Interestingly, different from healthcare-associated pneumonia, age, sex, and diabetes do not seem to pose a significant risk for the development of healthcare-associated meningitis following craniotomy [9].

\section{Central Nervous System Devices}

Devices commonly used in the neuro-ICU include EVDs, intracranial pressure (ICP) monitors, and lumbar drains. Most data on infectious complications are available for EVDs. As mentioned above, reported incidences on infections with these devices vary significantly, ranging from 0 to $22 \%$ depending on diagnostic method, study population, placement technique, and other modifiable risk factors [18-20]. Reported risk factors for VRI include the duration of catheterization, presence of intraventricular hemorrhage, insertion technique, and lack of infection control bundles [19]. While earlier data indicated that repeated CSF sampling poses a risk factor for VRI, a recent series did not show a higher risk of VRI but confirmed other well-documented risk factors (CSF leak, concurrent infection, long duration of EVDs) [21]. In a single-center study on the use of EVD, lumbar drain, and ICP monitors, the risk for infection was increased with increased drain opening, drain days, and lack of adherence to infection control bundle [22•]. However, when assessing risk for VRI selectively, drain days only remained significant (see Fig. 1 as an example of a duration-dependent increase of VRI). Furthermore, underlying diabetes mellitus and the presence of CSF leak posed a risk [22•]. A study on the pathogenic role of CSF drainage devices in postoperative neurosurgical patients showed that early device removal and avoiding implantation of a second device was associated with shorter illness duration [24].

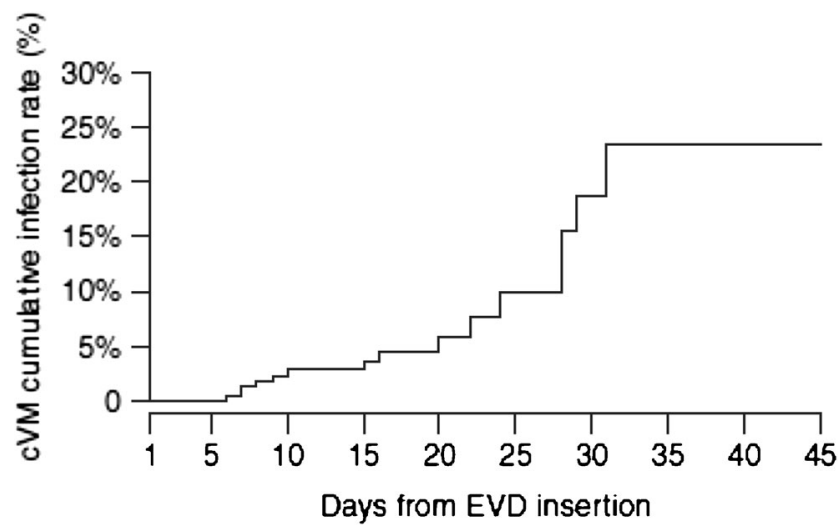

Fig. 1 EVD-related confirmed ventriculitis or meningitis (cVM), cumulative infection rate over time. (Modified and reprinted, from Citerio et al., External Ventricular and Lumbar Drain Device Infections in ICU Patients: A Prospective Multicenter Italian Study, Crit Care Med 2015; Volume 43, Issue 8, with permission from Wolters Kluwer Health, Inc.)

Antibiotic prophylaxis and the type of device used play a role, as well. Silver-impregnated EVDs showed some promise when first introduced; however, recent data did not show an overall reduction of VRI [25] but rather a preferential reduction in the number of gram-positive organisms [26]. The use of antibiotic-impregnated EVDs showed reduced rates of gram-positive infections ( 7.2 versus 12.1 infections per 1000 catheter days) with no significant reduction in gram-negative infections in a pooled meta-analysis [20]. Conventional EVDs with sustained prophylactic systemic antibiotic use was found equally effective for prevention of VRI [27], but this approach bares the risk of potential systemic adverse events. Clinical practice guidelines for surgical prophylaxis recommend periprocedural antibiotics at the time of device insertion, along with protocolized sterile placement techniques [28]. Multiple studies support the use of singledose prophylaxis regimens or systemic antibiotics for a maximum of 24-48 h after EVD placement [28, 29]. The benefit of antibiotic prophylaxis beyond this time frame, however, is not clear and may be associated with increased complications such as infection with resistant organisms or $C$. diff [29]. In a study of patients with mostly TBI with EVDs or ICP monitors, and prophylactic antibiotic use in $73 \%$ of the cohort, resistant organisms were more frequently found in the study versus control cohort; however, no significant difference was found in frequency of resistant organisms and $C$. diff rate when adjusting for ICU and hospital LOS and mechanical ventilation [30]. In contrary, limitation of systemic antimicrobial prophylaxis to the first $24 \mathrm{~h}$ after EVD placement in a single-center cohort significantly decreased the risk of $C$. diff infection without adverse effect on the rate of positive CSF cultures [29]. In the abovementioned recent study reporting equal effectiveness of antibiotic-coated EVDs 
and sustained antibiotic prophylaxis for conventional EVDs, there was a $3 \%$ incidence of $C$. diff infection, and $35 \%$ had healthcare-associated pneumonia, with $16 \%$ of those growing organisms that were resistant to the original antibiotics [27]. Less data are available on the use of intraventricular antibiotics, but such an approach may result in lower EVD infection rates: $2.7 \%$ vs. $11.9 \%$ in one study [31].

\section{Diagnosis}

New headache, fever, evidence of meningeal irritation, seizures, worsening mental status, nausea or lethargy in a patient with a history of neurosurgery, and head trauma or a CSF shunt or drain should raise suspicion for intracranial infectious complications [32••]. However, interpretation of clinical findings and CSF parameters are often difficult. Fever or increase in acute-phase proteins may be a manifestation of the underlying neurological disease or preceding procedure rather than a new infection [34]. Intracranial hemorrhage ( $\mathrm{ICH})$, local inflammatory reactions to neurosurgical interventions, and immunosuppression can drastically alter CSF profiles and create an aseptic inflammation that renders distinction from both viral and bacterial infections difficult. Various CSF biomarkers have been studied in the context of healthcare-associated CNS infections, but to date, no single CSF parameter can reliably predict or exclude HAVM. An elevated CSF lactate, procalcitonin, or their combination may be useful in diagnosing HAVM, and elevated serum procalcitonin may be useful in differentiating CSF abnormalities due to surgery or ICH from those due to bacterial infection [32••]. For CSF lactate, studies have shown cutoff values between 1.9 and $5.4 \mathrm{mmol} / \mathrm{L}$ to diagnose bacterial meningitis, but no single standard exists and not all data are conclusive, especially when a ventriculostomy is in place [35]. The cell index, assessing CSF cell counts in relation to serum counts, has been reported to have some value in diagnosing HAMV, even though the most convincing data (area under the curve of 0.825 ) for infection in hospitalized patients with $\mathrm{ICH}$ were documented in the setting of positive CSF culture [36]. Some experts suggest different, not yet validated, algorithms such as consideration of bacterial meningitis as unlikely with normal CSF glucose, CSF lactate $<4 \mathrm{mmol} / \mathrm{L}$ and negative Gram stain [10•]. A recently developed prediction rule to determine the presence of postoperative meningitis includes six variables (aneurysmal subarachnoid hemorrhage, CRP level, $\mathrm{CSF} /$ serum glucose ratio, CSF neutrophil count, CSF leak, and CSF lactate level), with an area under the curve of 0.94 for the prediction of infection [37], but this rule lacks broader validation. CSF cultures remain the gold standard, but cannot be relied upon as sole distinguishing feature for the decision to diagnose and treat, as it is estimated that up to $30 \%$ of HAMV are culture-negative [37]. Nucleic acid amplification tests, such as polymerase chain reaction, on CSF may both increase the ability to identify a pathogen and decrease the time to making a specific diagnosis [32••]. Although the addition of imaging is recommended, and distinct CT and MR imaging features of pyogenic ventriculitis have been described [38], sensitivity and specificity are not reliable enough to lean on them for guidance, in addition to practical considerations of obtaining imaging in critically ill patients. CSF markers that are being explored for aiding in the diagnosis of HAVM include CSF levels of IL- $1 \beta$, TNF- $\alpha$, IL-6, and IL-8 [39], but are not yet available or validated in a larger scheme.

Another important consideration in the diagnosis of HAVM is the differentiation of a true infection from a contamination or device colonization, as this will impact the therapeutic approach. The 2017 Infectious Disease Society of America guidelines also provide updated guidance on the interpretation of CSF profiles considering these possibilities $[32 \bullet \bullet$.

\section{Microbiology of Healthcare-associated Meningitis and Ventriculitis}

The most common organisms for HAVM used to be cutaneous gram-positive organisms such as coagulase-negative staphylococci, Staphylococcus aureus, and Propionibacterium acnes, but the proportion of gram-negative infections is increasing [10•], with the percentage of gram-negative infections now reported as high as $52 \%$ [15]. In a series of all types of HAVM, Acinetobacter spp. was the most common organism overall (31\%), followed by coagulase-negative staphylococci $(21 \%)$ and S. aureus (19\%) [40]. For EVD-related infections, specifically, the proportion of gram-negative infections has increased with at least $35 \%$ being gram-negative [20]. Mortality rates vary, similar to the reported rates of occurrence, based on study methodology and definitions used, and overall mortality has been reported as high as $27 \%$ with pathogen-specific mortality of $56 \%$ for A. baumannii versus 12-19\% for staphylococcal species [40]. Enterococcal meningitis is largely associated with device-related meningitis, and early treatment in combination with device removal is associated with favorable outcomes [41].

\section{Treatment of Healthcare-associated Meningitis and Ventriculitis}

Empiric antibiotic therapy should broadly cover the most likely pathogens involved, unless a causative agent has already been isolated. The selected antimicrobials must penetrate the blood-brain and blood-CSF barriers. Current guidelines 
recommend vancomycin, plus either an anti-pseudomonal cephalosporin or carbapenem [32••]. In case of beta-lactamallergy, fluoroquinolones or aztreonam are alternatives. The duration of treatment for HAVM is mostly based on common practice rather than true evidence, and usually spans 21 days for gram-negative, and 10-14 days for gram-positive meningitis [32••]. If the hardware is in place, removal and subsequent extended treatment are recommended [32••]. If an EVD is removed or exchanged, the duration of therapy is commonly limited to 5-7 days, while a longer duration of therapy for 10-14 days is usually recommended if the catheter is retained. A study on the pathogenic role of CSF drainage devices in postoperative neurosurgical patients showed that early device removal and avoidance of re-implantation resulted in shorter illness duration [24]. No antibiotics are currently FDAapproved for intrathecal use, and no consensus exists on indications for intrathecal treatment. Intrathecal therapy is often considered for severe ventriculitis, persistently positive CSF cultures, multidrug-resistant pathogens, intolerance of systemic antibiotic administration, or when device removal is not feasible [42]. Prophylactic catheter exchange has not been shown to significantly reduce the incidence of VRI $[19,43]$.

\section{Brain Injury-induced Immune Modulation}

Why are patients with acute brain injury so susceptible to infections? Acute brain injury leads to an inflammatory response that involves a complex interaction between central and peripheral cellular and soluble components, and is influenced by patient age, gender, genetics, mechanism and degree of injury, systemic and secondary injury, and therapeutic interventions $[44 \bullet \bullet]$. However, evidence from both animal models and humans indicates that brain-immune interactions become dysregulated after acute brain injury, resulting in a socalled brain injury-induced immunosuppression syndrome [46], with early activation and subsequent systemic depression that can last for weeks. While an inflammatory response is necessary for repair, a prolonged inflammation can lead to progressive neurodegeneration [47]. Although the bulk of data on systemic immune changes were obtained in ischemic stroke and traumatic brain injury (TBI), it is not unique to these conditions, and can also follow any other types of brain injury including brain surgery, subarachnoid hemorrhage, or spinal cord injury [48]. The inciting trigger is believed to be an intense activation of the hypothalamic-pituitary axis and the sympathetic nervous system with subsequent release of catecholamines [49]. Multiple modifications of the immune response have been described, including lymphocyte depletion, impaired monocyte function, reduced NK-cell activity, higher CD4/CD8 T cell ratio, and increased release of inflammatory cytokines with a shift in cytokine patterns [50-52]. Cellular regulation of inflammation at the site of brain injury leads to multiple interactions with the adaptive immune system, and systemic conditions that trigger an inflammatory response further complicate the interaction [44*0].

\section{Systemic Infectious Complications in Individual Acute Neurocritical Disease Processes}

\section{Traumatic Brain Injury (TBI)}

The incidence of HAI in patients with TBI has been reported as high as $41 \%$ [53], with the incidence of pneumonia consistently estimated at $30 \%$ or greater $[54,55]$, and rates of lower respiratory tract infections as high as $72 \%$ [56]. Surgical site infections are another common infectious complication with an incidence of 17-25\% [16]. Multiple independent risk factors have been identified for the development of HAI in TBI patients, including prolonged hospitalization, surgical intervention, CSF leak, nasal colonization of S. aureus, barbiturate use, and intubation with mechanical ventilation [16, 57]. Characteristics of severe TBI patients more likely to develop healthcare-associated pneumonia are male gender, younger age, longer duration of mechanical ventilation, intubation at the scene or in the emergency department, lower GCS score, higher Injury Severity Score, and thoracic injuries [58]. Ventilator-associated pneumonia (VAP) often occurs between day 5 and 11 of the ICU course, with a later, second, peak [59]. Factors independently associated with early-onset VAP include thoracic injury, Injury Severity Score and coma upon admission, whereas age in addition to Injury Severity Score and coma upon admission was independently associated with late-onset VAP [59]. In addition, the brain injury-induced immune changes have been implicated in the occurrence of infections in patients with TBI [44••]. Microbiological results for VAP in TBI patients predominantly consist of methicillin-sensitive $S$. aureus, Haemophilus influenzae, and Streptococcus pneumonia [60], with increasing numbers of Acinetobacter species in patients with early- and late-onset VAP [59].

Significant increase in morbidity due to HAI and association with worse outcomes for TBI patients has been shown in numerous studies: longer intensive care unit and hospital LOS, greater organ system dysfunction, more ventilator days [56], and worse neurological outcome [61], but it remains unclear whether HAI affect mortality in TBI [56, 62, 63]. Healthcare-associated pneumonia required longer inpatient rehabilitation stay [58] and has been found independently associated with an approximately sevenfold increase in odds of lower functional outcomes scores as far out as 5 years after injury [58]. For VAP specifically, survival rates at 1 month were lower, with $46 \%$ for early-onset VAP and $32 \%$ for 
late-onset VAP as compared to $69 \%$ for patients without VAP [59].

\section{Ischemic Stroke}

The most common post-stroke infections are urinary tract infections, with rates as high as 1 in 4 patients [64], and pneumonia, with rates as high as $25 \%$ [65]. However, not all of these infections are healthcare-associated-in one series, $24 \%$ of stroke patients presented with an infection on admission [66]. While pneumonia was long thought to occur largely as a result of dysphagia and aspiration, neurological impairment alone does not explain the high incidence of post-stroke infections, and accumulating evidence indicates a role of stroke-induced immune depression as outlined above [67]. Well-documented predictors of post-stroke infection include older age, stroke severity, a larger area of the infarct, and dysphagia [68]. For pneumonia specifically, older age [69-71], male sex [70, 72], current smoking [73], diabetes mellitus [72], hypertension [74], atrial fibrillation [65, 75], congestive heart failure $[71,75]$, chronic obstructive pulmonary disease [75], tachypnea and intubation [76], preexisting dependency $[75,77]$, stroke severity $[65,75,76]$, stroke subtype [76], dysphagia [76], and nutritional factors [65, 75] have been found to pose risk. Stroke-associated pneumonia not only increases morbidity and mortality [78] but also clinical outcomes after discharge [65] as well as healthcare costs and LOS [79]. The largest trial evaluating the effect of pneumonia on mortality in hospitalized stroke patients reported a $27 \%$ 30 -day mortality rate compared to $4 \%$ among patients without severe respiratory infections [80]. Patients with an infection at any time, whether on admission or healthcare-associated, are at nearly 7-fold greater odds of neurologic deterioration compared with patients without any infection; however, healthcare-associated infections in particular seem to be associated with a higher rate of neurologic deterioration [66].

\section{Intracerebral Hemorrhage (ICH)}

In a study of 202 patients with $\mathrm{ICH}$, at least one infection developed in $26 \%$ of patients, most commonly pneumonia $(18 \%$,$) UTI (12\%), meningitis or ventriculitis (3\%), and$ bacteremia (1\%) [81]. Risk factors for healthcare-associated pneumonia after ICH include age, active smoking, excess alcohol consumption, chronic obstructive pulmonary disease, premorbid dependence, ICH severity [73], dysphagia, inhospital aspiration, mechanical ventilation, tube feeding and tracheostomy [82, 83], infratentorial ICH location, [73], and hematoma volume [84, 85]. Infections in $\mathrm{ICH}$ patients are independently associated with prolonged hospital stay and greater odds of requiring a gastrostomy tube [81]. Healthcare-associated pneumonia specifically is reported to increase LOS, morbidity and mortality [82], and odds of poor outcome at discharge [81]. Additionally, infratentorial ICH, hematoma volume, and intraventricular extension-all risk factors of healthcare-associated infections - also have been shown to be risk factors for poor outcome after ICH $[84,85]$.

\section{Subarachnoid Hemorrhage (SAH)}

Incidence of HAI after SAH varies depending on the study and included patient population from 26 to $41 \%$ [86-88]. Risk factors include higher age, gender, poor clinical condition on admission, ICU admission, endotracheal intubation, tracheostomy placement, urinary catheter utilization, presence of IVH, and placement of an EVD [87, 89, 90]. Among intubated patients, $21 \%$ developed pneumonia, and $19 \%$ developed an infection during week 1 after aneurysmal SAH [88]. Despite the frequent use of EVDs, VRI remains a comparably rare complication in patients with $\mathrm{SAH}$, occurring in approximately $1 \%-5 \%$ of patients $[87,91]$. HAI in patients with SAH have independently been associated with poor outcomes [86], including poor functional outcome as well as mortality [87, 92, 93] and prolonged $\operatorname{LOS}[87,93]$. Additionally, there might be an interaction between HAI and delayed cerebral ischemia (DCI) that is not fully elucidated. Infection is a recognized precipitant of systemic inflammation leading to thrombocytosis, leukocytosis, and release of inflammatory cytokines [94], all of which have been implicated in the development of DCI [95-97]. Healthcare-associated bacteremia, pneumonia, UTI, and ventriculitis have all been shown to independently increase risk of DCI [86]. Vice versa, DCI predisposes patients to the development of HAI [87].

\section{Status Epilepticus}

While infections are a well-documented trigger for status epilepticus, data on incidence and impact of healthcareassociated infections among patients with status epilepticus are limited [98]. Respiratory and urinary tract infections are most common, with respiratory tract infections occurring at a rate of $24 \%$ [98-100]. Ventilator-associated pneumonia and sinusitis are the most common ICU-acquired infections [101]. Infections in this patient population are associated with prolonged medical care, higher healthcare resource consumption, refractory status epilepticus, higher morbidity and mortality independent of potential confounders, and unfavorable outcomes [98, 101].

\section{Clostridium difficile infection in the neuro-ICU}

Clostridium difficile infection and associated disease are serious infectious complications in hospitalized patients. In the ICU, $C$. diff is one of the most feared causes of HAI, and a $6 \%$ increase in the risk of mortality has been attributed to $C$. 
diff [102]. For neuro-ICUs specifically, the prevalence of 0.4 $0.5 \%$ has been reported, with an infection rate of 8.3/10.000 patient days [103]. In comparison, rates of $C$. diff in general ICUs were 15.5/10.000 patient days [104]. Risk factors for acquiring $C$. diff infection include older age, prolonged hospital stay, antibiotic use especially if for concurrent infection, immunosuppression, indwelling devices, laxative use, proton pump inhibitors, and mechanical ventilation [103]. In one series of neuro-ICU patients, the antibiotic class most frequently used in patients who subsequently developed $C$. diff were cephalosporins in $71 \%$ [103].

\section{Prevention Strategies}

The urgent need to develop novel ways to prevent HAI persists, as they increase morbidity, mortality, and healthcare utilization with worse outcomes. Preventive antibiotics have not shown benefit and are not recommended even in subpopulations with an acute neurological disease [105]. Infectionprevention bundles and standardized care have been the cornerstone for prevention for all types of HAI. Catheterassociated UTIs (CAUTIs) continue to be among the most common healthcare-associated infections, and their risk increases with length of catheterization [12]. Preventive strategies have focused on avoidance of catheter placement and discontinuation when possible, as well as protocol-driven care bundles [106]. For females, who are at greater risk for CAUTIs, external collection devices have shown promise as an alternative to indwelling catheters [107]; however, they are not applicable in urinary retention. Similar to efforts with CAUTIs, multidisciplinary quality improvements can be very effective in addressing the strongest risk factor for pneumonia, dysphagia [108]. An initiative to increase dysphagia screening among patients with stroke including online education for nurses, increased implementation of dysphagia screening and process improvements resulted in a decrease in the pneumonia prevalence from 6.5 to $2.8 \%$ among patients with stroke in a single-center study [109]. Early antibiotic prophylaxis, however, failed to show benefit for stroke functional outcome or mortality in a systematic review [110]. Furthermore, oropharyngeal decontamination with povidone-iodine did not prove to be effective in preventing VAP in a high-risk population of severely brain-injured patients or cerebral hemorrhage patients [60]. Lactoferrin, a component of the innate immune system with bacteriostatic effect was studied in mixed critically ill patients with mechanical ventilation. Twenty-eight percent of a developed healthcare-associated infection and lactoferrin had no effect on the occurrence of infections or antibiotic free days and outcomes [111]. Another topic of ongoing debate is early versus late tracheostomy in patients requiring ongoing ventilator support. Most studies have concluded that early versus late tracheostomy does not change mortality; however, there is converging evidence that early tracheostomy decreases ventilation days [112] and evidence-based protocols for early extubation can decrease the incidence of pneumonia [113, 114].

In line with the theory of brain injury-induced immune suppression, prevention of immunosuppression and subsequent infections has been attempted by $\beta$-adrenergic receptor blockade. In a retrospective analysis, use of beta-blockers was indeed associated with reduced risk of early death in patients with ischemic stroke [115], and both prospective and retrospective cohort studies have shown that the use of $\beta$ adrenergic receptor antagonists in adult TBI patients was independently associated with improved survival [116-118]. However, newer series with larger cohorts did not corroborate these findings and showed a lack of effect of beta-blocker therapy on infection rates in patients with ischemic strokes [119].

\section{Conclusion}

In conclusion, healthcare-associated infections remain a distinct challenge in the neuro-ICU population, not only due to high prevalence of cranial infections but also due to the specific characteristics of the neuro-ICU population rendering these patients especially prone to also systemic HAI. Prevention of healthcare-associated infections heavily relies on education, hygiene standards, and infection-prevention bundles, while most efforts to develop mechanistic strategies have mostly not shown benefit so far. The need for the development of additional strategies to lessen healthcare-associated infections remains.

\section{Compliance with Ethical Standards}

Conflict of Interest Katharina M. Busl declares no potential conflicts of interest.

Human and Animal Rights and Informed Consent This article does not contain any studies with human or animal subjects performed by any of the authors.

\section{References}

Papers of particular interest, published recently, have been highlighted as:

- Of importance

•. Of major importance

1.• Magill SS, O'Leary E, Janelle SJ, Thompson DL, Dumyati G, Nadle J, et al. Changes in prevalence of health care-associated infections in U.S. Hospitals. N Engl J Med. 2018;379(18):1732- 
44 Comprehensive overview of prevalence of all types of healthcare-associated infections in the recent years.

3. Burgmann H, Hiesmayr JM, Savey A, Bauer P, Metnitz B, Metnitz PG. Impact of nosocomial infections on clinical outcome and resource consumption in critically ill patients. Intensive Care Med. 2010;36(9):1597-601.

4. Razine R, Azzouzi A, Barkat A, Khoudri I, Hassouni F, Chefchaouni AC, et al. Prevalence of hospital-acquired infections in the university medical center of Rabat, Morocco. Int Arch Med. 2012;5(1):26.

5. Bonten MJ. Colonization pressure: a critical parameter in the epidemiology of antibiotic-resistant bacteria. Crit Care. 2012;16(4): 142.

6. Rosenthal VD, Maki DG, Salomao R, Moreno CA, Mehta Y, Higuera $\mathrm{F}$, et al. Device-associated nosocomial infections in 55 intensive care units of 8 developing countries. Ann Intern Med. 2006;145(8):582-91.

7. Shuman EK, Chenoweth CE. Recognition and prevention of healthcare-associated urinary tract infections in the intensive care unit. Crit Care Med. 2010;38(8 Suppl):S373-9.

8. Laborde G, Grosskopf U, Schmieder K, Harders A, Klimek L, Hardenack M, et al. Nosocomial infections in a neurosurgical intensive care unit. Anaesthesist. 1993;42(10):724-31.

9. Kourbeti IS, Vakis AF, Ziakas P, Karabetsos D, Potolidis E, Christou $\mathrm{S}$, et al. Infections in patients undergoing craniotomy: risk factors associated with post-craniotomy meningitis. J Neurosurg. 2015;122(5):1113-9.

10. Hussein K, Bitterman R, Shofty B, Paul M, Neuberger A. Management of post-neurosurgical meningitis: narrative review. Clin Microbiol Infect. 2017;23(9):621-8 Comprehensive review of management strategies for post-neurosurgical meningitis, including critical review of intrathecal antimicrobials.

12. Letica-Kriegel AS, Salmasian H, Vawdrey DK, Youngerman BE, Green RA, Furuya EY, et al. Identifying the risk factors for catheter-associated urinary tract infections: a large crosssectional study of six hospitals. BMJ Open. 2019;9(2):e022137.

13. Stocchetti N, Rossi S, Zanier ER, Colombo A, Beretta L, Citerio G. Pyrexia in head-injured patients admitted to intensive care. Intensive Care Med. 2002;28(11):1555-62.

14. Commichau C, Scarmeas N, Mayer SA. Risk factors for fever in the neurologic intensive care unit. Neurology. 2003;60(5):837-41.

15. Kurtaran B, Kuscu F, Ulu A, Inal AS, Komur S, Kibar F, et al. The causes of post-operative meningitis: the comparison of Gramnegative and Gram-positive pathogens. Turk Neurosurg. 2017.

16. Kourbeti IS, Vakis AF, Papadakis JA, Karabetsos DA, Bertsias G, Filippou M, et al. Infections in traumatic brain injury patients. Clin Microbiol Infect. 2012;18(4):359-64.

17. Reichert MC, Medeiros EA, Ferraz FA. Hospital-acquired meningitis in patients undergoing craniotomy: incidence, evolution, and risk factors. Am J Infect Control. 2002;30(3):158-64.

18. Citerio G, Signorini L, Bronco A, Vargiolu A, Rota M, Latronico $\mathrm{N}$, et al. External ventricular and lumbar drain device infections in ICU patients: a prospective multicenter Italian study. Crit Care Med. 2015;43(8):1630-7.

19. Lozier AP, Sciacca RR, Romagnoli MF, Connolly ES Jr. Ventriculostomy-related infections: a critical review of the literature. Neurosurgery. 2002;51(1):170-81 discussion 81-2.

20. Ramanan M, Lipman J, Shorr A, Shankar A. A meta-analysis of ventriculostomy-associated cerebrospinal fluid infections. BMC Infect Dis. 2015;15:3.

21. Thompson DR, Vlachos S, Patel S, Innocent S, Tolias C, Barkas $\mathrm{K}$. Recurrent sampling and ventriculostomy-associated infections: a case-control study. Acta Neurochir. 2018;160(5):1089-96.

22. Hussein K, Rabino G, Feder O, Eghbaryeh H, Zayyad H, Sviri G, et al. Risk factors for meningitis in neurosurgical patients with cerebrospinal fluid drains: prospective observational cohort study. Acta Neurochir. 2019;161(3):517-24 One of the most recent studies on CSF drain-related infections.

24. Soavi L, Rosina M, Stefini R, Fratianni A, Cadeo B, Magri S, et al. Post-neurosurgical meningitis: management of cerebrospinal fluid drainage catheters influences the evolution of infection. Surg Neurol Int. 2016;7(Suppl 39):S927-S34.

25. Nilsson A, Uvelius E, Cederberg D, Kronvall E. Silver-coated ventriculostomy catheters do not reduce rates of clinically diagnosed ventriculitis. World Neurosurg. 2018;117:e411-e6.

26. Atkinson RA, Fikrey L, Vail A, Patel HC. Silver-impregnated external-ventricular-drain-related cerebrospinal fluid infections: a meta-analysis. J Hosp Infect. 2016;92(3):263-72.

27. Albano S, Berman B, Fischberg G, Siddiqi J, Liu B, Khan Y, et al. Retrospective analysis of ventriculitis in external ventricular drains. Neurol Res Int. 2018;2018:adal18:5179356.

28. Bratzler DW, Dellinger EP, Olsen KM, Perl TM, Auwaerter PG, Bolon MK, et al. Clinical practice guidelines for antimicrobial prophylaxis in surgery. Am J Health Syst Pharm. 2013;70(3): 195-283.

29. Dellit TH, Chan JD, Fulton C, Pergamit RF, McNamara EA, Kim $\mathrm{LJ}$, et al. Reduction in Clostridium difficile infections among neurosurgical patients associated with discontinuation of antimicrobial prophylaxis for the duration of external ventricular drain placement. Infect Control Hosp Epidemiol. 2014;35(5):589-90.

30. Chauv S, Fontaine GV, Hoang QP, McKinney CB, Baldwin M, Buckel WR, et al. Risk of resistant organisms and Clostridium difficile with prolonged systemic antibiotic prophylaxis for central nervous system devices. Neurocrit Care. 2016;25(1):128-32.

31. Fu RZ, Anwar DR, Laban JT, Maratos EC, Minhas PS, Martin AJ. Pre-emptive intrathecal vancomycin therapy reduces external ventricular drain infection: a single centre retrospective case-control study. Br J Neurosurg. 2017;31(1):16-20.

32.• Tunkel AR, Hasbun R, Bhimraj A, Byers K, Kaplan SL, Michael Scheld W, et al. Infectious Diseases Society of America's clinical practice guidelines for healthcare-associated ventriculitis and meningitis. Clin Infect Dis. 2017;64(6):e34-65 The most updated edition of guidelines for definition and treatment of healthcare-associated ventriculitis and meningitis.

34. Diringer MN, Reaven NL, Funk SE, Uman GC. Elevated body temperature independently contributes to increased length of stay in neurologic intensive care unit patients. Crit Care Med. 2004;32(7):1489-95.

35. Hill E, Bleck TP, Singh K, Ouyang B, Busl KM. CSF lactate alone is not a reliable indicator of bacterial ventriculitis in patients with ventriculostomies. Clin Neurol Neurosurg. 2017;157:95-8.

36. Montes K, Jenkinson H, Habib OB, Esquenazi Y, Hasbun R. Corrected white blood cell count, cell index, and validation of a clinical model for the diagnosis of health care-associated ventriculitis and meningitis in adults with intracranial hemorrhage. Clin Neurol Neurosurg. 2019;178:36-41.

37. Hernandez Ortiz OH, Garcia Garcia HI, Munoz Ramirez F, Cardona Florez JS, Gil Valencia BA, Medina Mantilla SE, et al. Development of a prediction rule for diagnosing postoperative meningitis: a cross-sectional study. J Neurosurg. 2018;128(1): 262-71.

38. Fukui MB, Williams RL, Mudigonda S. CT and MR imaging features of pyogenic ventriculitis. AJNR Am J Neuroradiol. 2001;22(8):1510-6.

39. Liu ZH, Tu PH, Chen NY, Yip PK, Bowes AL, Lee CC, et al. Raised proinflammatory cytokine production within cerebrospinal fluid precedes fever onset in patients with neurosurgery-associated bacterial meningitis. Crit Care Med. 2015;43(11):2416-28.

40. Sipahi OR, Nazli Zeka A, Tasbakan M, Pullukcu H, Arda B, Yamazhan T, et al. Pooled analysis of 899 nosocomial meningitis episodes from Turkey. Turk J Med Sci. 2017;47(1):29-33. 
41. Khanum I, Anwar S, Farooque A. Enterococcal meningitis/ ventriculitis: a tertiary care experience. Asian J Neurosurg. 2019;14(1):102-5.

42. Stenehjem E, Armstrong WS. Central nervous system device infections. Infect Dis Clin N Am. 2012;26(1):89-110.

43. Lo CH, Spelman D, Bailey M, Cooper DJ, Rosenfeld JV, Brecknell JE. External ventricular drain infections are independent of drain duration: an argument against elective revision. J Neurosurg. 2007;106(3):378-83.

44.• Simon DW, McGeachy MJ, Bayir H, Clark RSB, Loane DJ, Kochanek PM. The far-reaching scope of neuroinflammation after traumatic brain injury. Nat Rev Neurol. 2017;13(9):572 In-depth analysis of changes in the immune system after acute traumatic brain injury.

46. Dirnagl U, Klehmet J, Braun JS, Harms H, Meisel C, Ziemssen T, et al. Stroke-induced immunodepression: experimental evidence and clinical relevance. Stroke. 2007;38(2 Suppl):770-3.

47. Kumar RG, Boles JA, Wagner AK. Chronic inflammation after severe traumatic brain injury: characterization and associations with outcome at 6 and 12 months postinjury. J Head Trauma Rehabil. 2015;30(6):369-81.

48. Catania A, Lonati C, Sordi A, Gatti S. Detrimental consequences of brain injury on peripheral cells. Brain Behav Immun. 2009;23(7):877-84.

49. Meisel C, Schwab JM, Prass K, Meisel A, Dirnagl U. Central nervous system injury-induced immune deficiency syndrome. Nat Rev Neurosci. 2005;6(10):775-86.

50. Offner H, Subramanian S, Parker SM, Afentoulis ME, Vandenbark AA, Hurn PD. Experimental stroke induces massive, rapid activation of the peripheral immune system. J Cereb Blood Flow Metab. 2006;26(5):654-65.

51. Prass K, Meisel C, Hoflich C, Braun J, Halle E, Wolf T, et al. Stroke-induced immunodeficiency promotes spontaneous bacterial infections and is mediated by sympathetic activation reversal by poststroke T helper cell type 1-like immunostimulation. J Exp Med. 2003;198(5):725-36.

52. Walter U, Kolbaske S, Patejdl R, Steinhagen V, Abu-Mugheisib M, Grossmann A, et al. Insular stroke is associated with acute sympathetic hyperactivation and immunodepression. Eur J Neurol. 2013;20(1):153-9.

53. Piek J, Chesnut RM, Marshall LF, van Berkum-Clark M, Klauber MR, Blunt BA, et al. Extracranial complications of severe head injury. J Neurosurg. 1992;77(6):901-7.

54. Richards MJ, Edwards JR, Culver DH, Gaynes RP. Nosocomial infections in combined medical-surgical intensive care units in the United States. Infect Control Hosp Epidemiol. 2000;21(8):510-5.

55. Wang KW, Chen HJ, Lu K, Liliang PC, Huang CK, Tang PL, et al. Pneumonia in patients with severe head injury: incidence, risk factors, and outcomes. J Neurosurg. 2013;118(2):358-63.

56. Zygun DA, Zuege DJ, Boiteau PJ, Laupland KB, Henderson EA, Kortbeek JB, et al. Ventilator-associated pneumonia in severe traumatic brain injury. Neurocrit Care. 2006;5(2):108-14.

57. Kourbeti IS, Papadakis JA, Neophytou C, Filippou M, Ioannou A, Karabetsos DA, et al. Infections in patients with traumatic brain injury who undergo neurosurgery. Br J Neurosurg. 2011;25(1):915.

58. Kesinger MR, Kumar RG, Wagner AK, Puyana JC, Peitzman AP, Billiar TR, et al. Hospital-acquired pneumonia is an independent predictor of poor global outcome in severe traumatic brain injury up to 5 years after discharge. J Trauma Acute Care Surg. 2015;78(2):396-402.

59. Jovanovic B, Milan Z, Markovic-Denic L, Djuric O, Radinovic K, Doklestic K, et al. Risk factors for ventilator-associated pneumonia in patients with severe traumatic brain injury in a Serbian trauma centre. Int J Infect Dis. 2015;38:46-51.
60. Seguin P, Laviolle B, Dahyot-Fizelier C, Dumont R, Veber B, Gergaud S, et al. Effect of oropharyngeal povidone-iodine preventive oral care on ventilator-associated pneumonia in severely brain-injured or cerebral hemorrhage patients: a multicenter, randomized controlled trial. Crit Care Med. 2014;42(1):1-8.

61. Schirmer-Mikalsen K, Moen KG, Skandsen T, Vik A, Klepstad P. Intensive care and traumatic brain injury after the introduction of a treatment protocol: a prospective study. Acta Anaesthesiol Scand. 2013;57(1):46-55.

62. Cardozo Junior LC, Silva RR. Sepsis in intensive care unit patients with traumatic brain injury: factors associated with higher mortality. Rev Bras Ter Intensiva. 2014;26(2):148-54.

63. Selassie AW, Fakhry SM, Ford DW. Population-based study of the risk of in-hospital death after traumatic brain injury: the role of sepsis. J Trauma. 2011;71(5):1226-34.

64. Langhorne P, Stott DJ, Robertson L, MacDonald J, Jones L, McAlpine C, et al. Medical complications after stroke: a multicenter study. Stroke. 2000;31(6):1223-9.

65. NanZhu Y, Xin L, Xianghua Y, Jun C, Min L. Risk factors analysis of nosocomial pneumonia in elderly patients with acute cerebral infraction. Medicine (Baltimore). 2019;98(13):e15045.

66. Boehme AK, Kumar AD, Dorsey AM, Siegler JE, Aswani MS, Lyerly MJ, et al. Infections present on admission compared with hospital-acquired infections in acute ischemic stroke patients. J Stroke Cerebrovasc Dis : the official journal of National Stroke Association. 2013;22(8):e582-9.

67. Klehmet J, Harms H, Richter M, Prass K, Volk HD, Dirnagl U, et al. Stroke-induced immunodepression and post-stroke infections: lessons from the preventive antibacterial therapy in stroke trial. Neuroscience. 2009;158(3):1184-93.

68. Hannawi Y, Hannawi B, Rao CP, Suarez JI, Bershad EM. Strokeassociated pneumonia: major advances and obstacles. Cerebrovasc Dis. 2013;35(5):430-43.

69. Chumbler NR, Williams LS, Wells CK, Lo AC, Nadeau S, Peixoto AJ, et al. Derivation and validation of a clinical system for predicting pneumonia in acute stroke. Neuroepidemiology. 2010;34(4):193-9.

70. Hoffmann S, Malzahn U, Harms H, Koennecke HC, Berger K, Kalic M, et al. Development of a clinical score (A2DS2) to predict pneumonia in acute ischemic stroke. Stroke. 2012;43(10):261723.

71. Ovbiagele B, Hills NK, Saver JL, Johnston SC, California Acute Stroke Prototype Registry I. Frequency and determinants of pneumonia and urinary tract infection during stroke hospitalization. J Stroke Cerebrovasc Dis : the official journal of National Stroke Association. 2006;15(5):209-13.

72. Aslanyan S, Weir CJ, Diener HC, Kaste M, Lees KR, Committee GIS, et al. Pneumonia and urinary tract infection after acute ischaemic stroke: a tertiary analysis of the GAIN International trial. Eur J Neurol. 2004;11(1):49-53.

73. Ji R, Shen H, Pan Y, Du W, Wang P, Liu G, et al. Risk score to predict hospital-acquired pneumonia after spontaneous intracerebral hemorrhage. Stroke. 2014;45(9):2620-8.

74. Ding R, Logemann JA. Pneumonia in stroke patients: a retrospective study. Dysphagia. 2000;15(2):51-7.

75. Ji R, Shen H, Pan Y, Wang P, Liu G, Wang Y, et al. Novel risk score to predict pneumonia after acute ischemic stroke. Stroke. 2013;44(5):1303-9.

76. Walter U, Knoblich R, Steinhagen V, Donat M, Benecke R, Kloth A. Predictors of pneumonia in acute stroke patients admitted to a neurological intensive care unit. J Neurol. 2007;254(10):1323-9.

77. Sellars C, Bowie L, Bagg J, Sweeney MP, Miller H, Tilston J, et al. Risk factors for chest infection in acute stroke: a prospective cohort study. Stroke. 2007;38(8):2284-91. 
78. Westendorp WF, Nederkoorn PJ, Vermeij JD, Dijkgraaf MG, van de Beek D. Post-stroke infection: a systematic review and metaanalysis. BMC Neurol. 2011;11:110.

79. Ingeman A, Andersen G, Hundborg HH, Svendsen ML, Johnsen SP. In-hospital medical complications, length of stay, and mortality among stroke unit patients. Stroke. 2011;42(11):3214-8.

80. Katzan IL, Cebul RD, Husak SH, Dawson NV, Baker DW. The effect of pneumonia on mortality among patients hospitalized for acute stroke. Neurology. 2003;60(4):620-5.

81. Hinduja A, Dibu J, Achi E, Patel A, Samant R, Yaghi S. Nosocomial infections in patients with spontaneous intracerebral hemorrhage. Am J Crit Care : an official publication, American Association of Critical-Care Nurses. 2015;24(3):227-31.

82. Alsumrain M, Melillo N, Debari VA, Kirmani J, Moussavi M, Doraiswamy V, et al. Predictors and outcomes of pneumonia in patients with spontaneous intracerebral hemorrhage. J Intensive Care Med. 2013;28(2):118-23.

83. Divani AA, Hevesi M, Pulivarthi S, Luo X, Souslian F, Suarez JI, et al. Predictors of nosocomial pneumonia in intracerebral hemorrhage patients: a multi-center observational study. Neurocrit Care. 2015;22(2):234-42.

84. Hwang BY, Appelboom G, Kellner CP, Carpenter AM, Kellner MA, Gigante PR, et al. Clinical grading scales in intracerebral hemorrhage. Neurocrit Care. 2010;13(1):141-51.

85. Ji R, Shen H, Pan Y, Wang P, Liu G, Wang Y, et al. A novel risk score to predict 1-year functional outcome after intracerebral hemorrhage and comparison with existing scores. Crit Care. 2013;17(6):R275.

86. Foreman PM, Chua M, Harrigan MR, Fisher WS 3rd, Vyas NA, Lipsky RH, et al. Association of nosocomial infections with delayed cerebral ischemia in aneurysmal subarachnoid hemorrhage. J Neurosurg. 2016;125(6):1383-9 1-7.

87. Frontera JA, Fernandez A, Schmidt JM, Claassen J, Wartenberg $\mathrm{KE}$, Badjatia N, et al. Impact of nosocomial infectious complications after subarachnoid hemorrhage. Neurosurgery. 2008;62(1): 80-7 discussion 7.

88. Laban KG, Rinkel GJ, Vergouwen MD. Nosocomial infections after aneurysmal subarachnoid hemorrhage: time course and causative pathogens. Int J Stroke : official journal of the International Stroke Society. 2015;10(5):763-6.

89. Cinotti R, Dordonnat-Moynard A, Feuillet F, Roquilly A, Rondeau N, Lepelletier D, et al. Risk factors and pathogens involved in early ventilator-acquired pneumonia in patients with severe subarachnoid hemorrhage. Eur J Clin Microbiol Infect Dis. 2014;33(5):823-30.

90. Savardekar A, Gyurmey T, Agarwal R, Podder S, Mohindra S, Gupta SK, et al. Incidence, risk factors, and outcome of postoperative pneumonia after microsurgical clipping of ruptured intracranial aneurysms. Surg Neurol Int. 2013;4:24.

91. Singh TD, Maloney P, Rabinstein AA, Hocker S. Significance of routine cerebrospinal fluid analysis in subarachnoid hemorrhage. $\mathrm{J}$ Neurosurg Sci. 2015

92. Douds GL, Tadzong B, Agarwal AD, Krishnamurthy S, Lehman $\mathrm{EB}$, Cockroft KM. Influence of fever and hospital-acquired infection on the incidence of delayed neurological deficit and poor outcome after aneurysmal subarachnoid hemorrhage. Neurol Res Int. 2012;2012:479865.

93. Vergouwen MD, Fang J, Casaubon LK, Stamplecoski M, Robertson A, Kapral MK, et al. Higher incidence of in-hospital complications in patients with clipped versus coiled ruptured intracranial aneurysms. Stroke. 2011;42(11):3093-8.

94. Oda S, Hirasawa H, Shiga H, Nakanishi K, Matsuda K, Nakamua M. Sequential measurement of IL-6 blood levels in patients with systemic inflammatory response syndrome (SIRS)/sepsis. Cytokine. 2005;29(4):169-75.
95. Dhar R, Diringer MN. The burden of the systemic inflammatory response predicts vasospasm and outcome after subarachnoid hemorrhage. Neurocrit Care. 2008;8(3):404-12.

96. Kasius KM, Frijns CJ, Algra A, Rinkel GJ. Association of platelet and leukocyte counts with delayed cerebral ischemia in aneurysmal subarachnoid hemorrhage. Cerebrovasc Dis. 2010;29(6):57683.

97. Muroi C, Hugelshofer M, Seule M, Tastan I, Fujioka M, Mishima $\mathrm{K}$, et al. Correlation among systemic inflammatory parameter, occurrence of delayed neurological deficits, and outcome after aneurysmal subarachnoid hemorrhage. Neurosurgery. 2013;72(3):367-75 discussion 75.

98. Semmlack S, Tschudin-Sutter S, Widmer AF, Valenca M, Ruegg $\mathrm{S}$, Marsch S, et al. Independent impact of infections on the course and outcome of status epilepticus: a 10-year cohort study. J Neurol. 2016;263(7):1303-13.

99. Sutter R, Tschudin-Sutter S, Grize L, Fuhr P, Bonten MJ, Widmer $\mathrm{AF}$, et al. Associations between infections and clinical outcome parameters in status epilepticus: a retrospective 5-year cohort study. Epilepsia. 2012;53(9):1489-97.

100. Zelano J, Moller F, Dobesberger J, Trinka E, Kumlien E. Infections in status epilepticus: a retrospective 5-year cohort study. Seizure. 2014;23(8):603-6.

101. Ala-Kokko TI, Saynajakangas P, Laurila P, Ohtonen P, Laurila JJ, Syrjala $\mathrm{H}$. Incidence of infections in patients with status epilepticus requiring intensive care and effect on resource utilization. Anaesth Intensive Care. 2006;34(5):639-44.

102. Kenneally C, Rosini JM, Skrupky LP, Doherty JA, Hollands JM, Martinez E, et al. Analysis of 30-day mortality for clostridium difficile-associated disease in the ICU setting. Chest. 2007;132(2):418-24.

103. Tripathy S, Nair P, Rothburn M. Clostridium difficile associated disease in a neurointensive care unit. Front Neurol. 2013;4:82.

104. Crabtree SJ, Robertson JL, Chung KK, Renz EM, Wolf SE, Hospenthal DR, et al. Clostridium difficile infections in patients with severe burns. Burns. 2011;37(1):42-8.

105. Zheng F, Spreckelsen NV, Zhang X, Stavrinou P, Timmer M, Dohmen C, et al. Should preventive antibiotics be used in patients with acute stroke? A systematic review and meta-analysis of randomized controlled trials. PLoS One. 2017;12(10):e0186607.

106. Liang CC, Huang TJ, Yang SH, Su JY, Mu PF, Curia M. Prevention of catheter-associated urinary tract infection in neurological post-operation patients: a best practice implementation project. JBI Database Syst Rev Implement Rep. 2019;17(6): 1256-67.

107. Beeson T, Davis C. Urinary management with an external female collection device. J Wound Ostomy Continence Nurs. 2018;45(2): 187-9.

108. Marciniak C, Korutz AW, Lin E, Roth E, Welty L, Lovell L. Examination of selected clinical factors and medication use as risk factors for pneumonia during stroke rehabilitation: a case-control study. Am J Phys Med Rehabil. 2009;88(1):30-8.

109. Titsworth WL, Abram J, Fullerton A, Hester J, Guin P, Waters MF, et al. Prospective quality initiative to maximize dysphagia screening reduces hospital-acquired pneumonia prevalence in patients with stroke. Stroke. 2013;44(11):3154-60.

110. van de Beek D, Wijdicks EF, Vermeij FH, de Haan RJ, Prins JM, Spanjaard L, et al. Preventive antibiotics for infections in acute stroke: a systematic review and meta-analysis. Arch Neurol. 2009;66(9):1076-81.

111. Muscedere J, Maslove DM, Boyd JG, O'Callaghan N, Sibley S, Reynolds S, et al. Prevention of nosocomial infections in critically ill patients with lactoferrin: a randomized, double-blind, placebocontrolled study. Crit Care Med. 2018;46(9):1450-6.

112. Holevar M, Dunham JC, Brautigan R, Clancy TV, Como JJ, Ebert $\mathrm{JB}$, et al. Practice management guidelines for timing of 
tracheostomy: the EAST Practice Management Guidelines Work Group. J Trauma. 2009;67(4):870-4.

113. Croce MA, Brasel KJ, Coimbra R, Adams CA Jr, Miller PR, Pasquale MD, et al. National Trauma Institute prospective evaluation of the ventilator bundle in trauma patients: does it really work? J Trauma Acute Care Surg. 2013;74(2):354-60 discussion 60-2.

114. Heimes J, Braxton C, Nazir N, Shik N, Carlton E, Lansford T, et al. Implementation and enforcement of ventilator-associated pneumonia prevention strategies in trauma patients. Surg Infect. 2011;12(2):99-103.

115. Dziedzic T, Slowik A, Pera J, Szczudlik A. Beta-blockers reduce the risk of early death in ischemic stroke. J Neurol Sci. 2007;252(1):53-6.

116. Arbabi S, Campion EM, Hemmila MR, Barker M, Dimo M, Ahrns KS, et al. Beta-blocker use is associated with improved outcomes in adult trauma patients. J Trauma. 2007;62(1):56-61 discussion -2 .

117. Cotton BA, Snodgrass KB, Fleming SB, Carpenter RO, Kemp $\mathrm{CD}$, Arbogast PG, et al. Beta-blocker exposure is associated with improved survival after severe traumatic brain injury. J Trauma. 2007;62(1):26-33 discussion -5.

118. Inaba K, Teixeira PG, David JS, Chan LS, Salim A, Brown C, et al. Beta-blockers in isolated blunt head injury. J Am Coll Surg. 2008;206(3):432-8.

119. Maier IL, Becker JC, Leyhe JR, Schnieder M, Behme D, Psychogios MN, et al. Influence of beta-blocker therapy on the risk of infections and death in patients at high risk for stroke induced immunodepression. PLoS One. 2018;13(4):e0196174 Study to determine whether beta-blockade affects risk of infection in stroke patients, based on the theory of brain-induce immunosuppression-with negative results in this trial.

Publisher's Note Springer Nature remains neutral with regard to jurisdictional claims in published maps and institutional affiliations. 